\section{Poor predicting values in obtaining non-insulin requiring remission using proinsulin/C-peptide ratios}

Dear Sir,

Herewith we would like to comment on the article of O. Snorgaard et al., [1]. In their discussion the authors suggest that a high (above 0.024 ) proinsulin/C-peptide ratio may be of value in predicting the induction of remission on cyclosporin. A further specification of this conclusion is warranted; first it is shown in Figure 3 that although proinsulin/C-peptide ratios are lower in the cyclosporintreated group vs. the placebo group, this effect is independent of non-insulin-requiring remission (NIR). From the data given in Table 3 we calculated the positive and negative predictive value (PPV and NPV) of the ratio above and below 0.024. Predicting for NIR in the cyclosporin treated and placebo group, the values were respectively: cyclosporin PPV 64\% and NPV 58\%, placebo PPV $28 \%$ and NPV $66 \%$. From these data it is clear that although the PPV is considerably higher in the cyclosporin group, the NPV is higher in the placebo group. We feel that considerable caution is indicated before the proinsulin/C-peptide ratio can be applied as a predictor of outcome on a large scale.

Yours sincerely,

H.E. Brussaard and B. Bravenboer

\section{References}

1. Snorgaard O, Hartling SG, Binder C (1990) Proinsulin and C-peptide at onset and during 12 months cyclosporin treatment of Type 1 (insulin-dependent) diabetes mellitus. Diabetologia 33: $36-42$

Drs. H.E. Brussaard

and B. Bravenboer

Utrecht University Hospital

P.O. Box 85500

NL-3508 GA Utrecht

The Netherlands

\section{Effect of protein kinase $\mathrm{C}$ modulators on the leucocyte $\mathrm{Na}^{+} / \mathrm{H}^{+}$antiport in Type 1 (insulin-dependent) diabetic subjects with albuminuria}

Dear Sir,

Recently L.L. Ng et al. reported an elevated leucocyte $\mathrm{Na}^{+} / \mathrm{H}^{+}$ antiport activity in Type 1 (insulin-dependent) diabetic subjects with albuminuria as compared to patients without albuminuria [1]. The patients were defined as albuminuric if the average of three early morning urine albumin/creatinine ratios were above $2.0 \mathrm{mg} / \mathrm{mmol}$ [2]. The predictive value of this cut off level is $35 \%$ for identification of an overnight urinary albumin excretion rate $>30 \mu \mathrm{g} / \mathrm{min}$ [2]. Thus, $65 \%$ of the patients will have an overnight urinary albumin excretion rate below $30 \mu \mathrm{g} / \mathrm{min}$ (false positives). Overt and incipient diabetic nephropathy should be defined by quantitative tests according to general accepted criteria [3].

Yours sincerely,

H.-H.Parving

\section{References}

1. Ng LL, Simmons D, Frighi V, Garrido MC, Bomford J (1990) Effect of protein kinase C modulators on the leucocyte $\mathrm{Na}^{+} / \mathrm{H}^{+}$antiport in Type 1 (insulin-dependent) diabetic subjects with albuminuria. Diabetologia 33: 278-284

2. Gatling W, Knight C, Mullee MA, Hill RD(1987) Microalbuminuria in diabetes: a population study of the prevalence and an assessment of three screening tests. Diab Med 5: 343-347

3. Mogensen CE, Chachati A, Christensen CK et al. (1985) Microalbuminuria. An early marker of renal involvement in diabetes. Uremia Invest 9: 85-95

Dr.H.-H. Parving

Hviddre Hospital

Emiliekildevej 1

DK-2930 Klampenborg

Denmark

\section{Repeatability of the oral glucose tolerance test for the diagnosis of impaired glucose tolerance and diabetes mellitus}

Dear Sir,

The recent paper by Eriksson and Lindgärde [1] presented a survey of 45-47 year old men, which aimed to identify both impaired glucose tolerant (IGT) and diabetic subjects. They performed an oral glucose tolerance test (OGTT) with a glucose load of $30 \mathrm{~g} / \mathrm{m}^{2}$ and selected a group of 889 subjects who were considered to have abnormal glucose tolerance, those with a $2 \mathrm{~h}$ glucose concentration greater than $6.7 \mathrm{mmol} / \mathrm{l}$. One month later, a second OGTT was performed.

They commented on the 'individual wide fluctuation', and 'that only $31 \%$ of those originally meeting the WHO criterion of IGT [2] had a comparable test outcome' on the second OGTT and that 'reproducibility was highest in the diabetic group'. The low reproducibility of $45 \%$ in the group diagnosed diabetic at the first examination is of even more concern than the poor reproducibility of the IGT di- 
agnosis, especially as there were $25 \%$ reverting to normal glucose tolerance. This reversion would appear to be due to natural fluctuations in glucose concentrations, and not to be due to a change in diet or medication, as the men had no knowledge about the results of their initial examination.

Our data, from the Paris Prospective Study [3], are shown in Table 1 . This study involved 44-55 year-old working men, the time between the two $75 \mathrm{~g}$ OGTTs was on average two and a half years (between 1.2 and 4.3 years), and the WHO criteria [2] were used to define IGT and diabetes. The second OGTT was not performed on those who had been identified as being diabetic by their general practitioner, before the second OGTT. There were $26(0.5 \%)$ such new diabetic patients from those classed normal glucose tolerant, 12 $(2 \%)$ from those classed IGT and $15(12 \%)$ from those classed diabetic on the first OGTT. Our results are strikingly similar to those of the Swedish study, both in those diagnosed IGT and those diagnosed diabetic at the first examination, despite the different time delays between tests, and the different glucose loads used.

The results on the diagnosis of IGT are similar to those reviewed by Yudkin et al. [4]: for subjects having a repeated OGTT within one year, $21-56 \%$ remained IGT, and 3-16\% developed diabetes; for an OGTT repeated within 1 to 12 years, between $20-50 \%$ remained IGT, $10-47 \%$ became diabetic. Yudkin et al. suggested that insulin should be measured in IGT subjects, to discriminate between those who deteriorate to diabetes who have a failing Beta-cell function, and those who remain IGT, with persistent hyperinsulinaemia. Two reports on the risk factors for deterioration of IGT subjects to diabetes, have shown that such IGT subjects already have a diminished $2 \mathrm{~h}$ insulin response to a glucose load $[5,6]$. The second of these reports was on the Paris Prospective Study. If we Iook at this idea in a very simplistic, univariate fashion for the 100 subjects in the Paris Prospective Study who were initially diagnosed as diabetic by the OGTT, this trend was also apparent, though the difference was not always significant. For fasting insulin concentrations: $155 \pm$ $20 \mathrm{pmol} / \mathrm{l}$ (mean $\pm \mathrm{SEM}$ ) for those reverting to IGT, $146 \pm 14 \mathrm{pmol} / 1$ for those remaining diabetic, NS for the $2 \mathrm{~h}$ insulin concentrations: $609 \pm 59 \mathrm{pmol} / 1$ for those reverting to IGT, $437 \pm 41 \mathrm{pmol} / /$ for those remaining diabetic, $p<0.01$.

The measurement of blood glucose is itself subject to analytic error [7]. Depending on the laboratory method used, the coefficient of variation can be as high as $8 \%$, thus a concentration of $8 \mathrm{mmol} / \mathrm{l}$ lies somewhere between 6.7 and $9.3 \mathrm{mmol} / \mathrm{l}$ with a probability of $95 \%$.

The most recent 'Position Statement' on the screening for diabetes, from the American Diabetes Association [8] suggested that the risk factors of the individual should be used concurrently with their glucose tolerance. These risk factors are (1) family history of diabetes (2) obesity (3) race (4) age (5) previous diagnosis of IGT (6) hypertension or significant hyperlipidaemia. In the Paris Prospective Study, for the group initially classed IGT, none of the mean

Table 1. Classification of subjects as normoglycaemic, impaired glucose tolerant (IGT) and diabetic according to WHO criteria following a first and a second oral glucose tolerance test (OGTT)

\begin{tabular}{llll}
\hline 1st OGTT Normo & 2nd OGTT Diabetic Total \\
& IGT
\end{tabular}

Eriksson and Lindgärde [1], OGTTs conducted within one month

\begin{tabular}{lrrcr} 
Normoglycaemic & $426(88 \%)$ & $52(11 \%)$ & $7(1 \%)$ & 485 \\
IGT & $221(63 \%)$ & $109(31 \%)$ & $23(7 \%)$ & 353 \\
Diabetic & $13(25 \%)$ & $15(29 \%)$ & $23(45 \%)$ & 51 \\
Total & $660(74 \%)$ & $176(20 \%)$ & $53(6 \%)$ & 889 \\
Paris Prospective Study data [2], OGTTs conducted within & \\
$21 / 2$ years, on average & & & \\
Normoglycaemic & $4645(96 \%)$ & $174(4 \%)$ & $27(0.6 \%)$ & 4846 \\
IGT & $333(69 \%)$ & $127(26 \%)$ & $26(5 \%)$ & 486 \\
Diabetic & $30(28 \%)$ & $32(29 \%)$ & $47(43 \%)$ & 109 \\
Total & $5008(92 \%)$ & $333(6 \%)$ & $100(2 \%)$ & 5441 \\
\hline
\end{tabular}

values of these factors differed significantly for subjects later classified as diabetic, (either by the second OGTT or by their general practitioner), in comparison with those who remained IGT. The same was the case for those initially classed as diabetic.

The OGTT should be used with caution when diagnosing subjects either as IGT or diabetic. It was developed partly on the basis of epidemiological arguments, and a satisfactory solution to the diagnosis of diabetes in individuals must still be sought.

Yours sincerely,

B. Balkau and E. Eschwège

\section{References}

1. Eriksson KF, Lindgärde F (1990) Impaired glucose tolerance in a middle-aged male urban population: a new approach for identifying high-risk cases. Diabetologia 33: 526-531

2. WHO Study Group (1985) Diabetes mellitus. WHO Tech Rep Series $\mathrm{N}^{0} 727$, WHO Geneva

3. Ducimetière P, Eschwège E, Papoz L, Richard JL, Claude JR, Rosselin GE (1980) Relationship of plasma insulin levels to the incidence of myocardial infarction and coronary heart disease mortality in a middle-aged population. Diabetologia 19: 205-210

4. Yudkin JS, Alberti KGMM, McLarty DG, Swai ABM (1990) Impaired glucose tolerance. Is it a risk factor for diabetes or a diagnostic ragbag? BMJ 301: 397-402

5. Sicree RA, Zimmet PZ, King HOM, Coventry JS (1987) Plasma insulin response among Nauruans. Prediction of deterioration in glucose tolerance over 6 yr. Diabetes $36: 179-186$

6. Charles MA, Fontbonne A, Eschwège E (1988) Risk factors of Type 2 (non-insulin-dependent) diabetes in a Caucasian population. Diabetologia 31:479 (Abstract)

7. Burrin JM, Alberti KGMM (1990) What is blood glucose: can it be measured? Diab Med 7: 199-206

8. American Diabetes Association (1990) Screening for diabetes. Diabetes Care 13: 7-9

B. Balkau

INSERM U21

16 ave Paul-Vaillant-Couturier

F-94807 Villejuif Cedex

France

\section{Proinsulin conversion intermediates: a possible source of confusion}

\section{Dear Sir,}

In their recent paper [1], Yudkin et al. describe the measurement of proinsulin, insulin and a major proinsulin conversion intermediate in the circulation of Type 2 (non-insulin-dependent) diabetic subjects. May I draw the attention of your readers to a possible source of confusion with regard to the identity of the conversion intermediate, in both the title and the text of this paper. Throughout this and previous papers $[2,3]$, the authors refer to "32-33 split proinsulin". Such an intermediate does indeed arise during proinsulin conversion as a result of an endoproteolytic attack $\mathrm{C}$-terminal to Arg 32 (i.e. at the B-chain/C-peptide junction) [4]. It is, however, generally accepted that within Beta-cell granules (where conversion arises [5]) residual C-terminal basic amino acids left from such an endoproteolytic event are rapidly removed by carboxypeptidase $\mathrm{H}[6$, 7]. The major conversion intermediates found in the Beta cell, or indeed in the circulation, have thus been shown to be des 31,32- or des 64,65-split proinsulin (the latter being generated by cleavage at the C-peptide/A-chain junction followed by carboxypeptidase $\mathrm{H}$ trimming) $[7,8]$. Of these two products, it is the des 31,32 -form which predominates [8].

The authors have themselves stressed [2] that their analytical technique, although indeed sensitive and specific [2], cannot de- 